\title{
THE MULTIPLE TEMPORALITIES OF CHANGEFUL ORGANIZATIONAL PRACTICE
}

\author{
BARBARA SIMPSON \\ Strathclyde Business School \\ 199 Cathedral Street, Glasgow G4 0QU, United Kingdom \\ JOHN SILLINCE \\ Newcastle University Business School, United Kingdom
}

\section{INTRODUCTION}

According to Pettigrew, Woodman \& Cameron (2001), what it is that managers actually do in strategic organizational change remains largely 'black-boxed'. In this paper, we suggest that 'talk' offers the possibility of prising open this black box of managerial practice to reveal those less visible, more fragile and more ephemeral aspects of process and context that have often eluded researchers in this field. There is already an emergent literature that recognises organizations as materially constituted by narrative (e.g. Cooren, 1999; Cooren, Taylor, \& Van Every, 2006) and the practices of talk (Boje, Oswick, \& Ford, 2004), but in our view, these studies have tended to neglect the emergent potential of agentic action. To begin to address this gap, we adopt a processual approach that explicitly acknowledges the ongoing and emergent nature of managerial practice (e.g. Tsoukas \& Chia, 2002; Weick, 1998). Our main contribution is a multi-temporal, rather than multi-level, analysis of strategic organizational change.

\section{THEORY DEVELOPMENT}

Drawing on the temporal continuity of past, present and future as articulated by Mead (1932), the linguistic pragmatics of Austin (1962) and Searle (1969), and a conception of agency as inherently social and dynamic (Emirbayer \& Mische, 1998), we understand talk as the ongoing gesture and response of conversation, where it is the intentional and contextual aspects of this talk that actually perform, rather than merely describe, the actions of change (Taylor, et al., 1996). This approach reflects recent developments in the organizational literature on practice (e.g. Miettinen, Samra-Fredericks, \& Yanow, 2009), where what people actually do is understood as a temporal unfolding of agentic action (Simpson, 2009; 2013). Thus temporality and agency are key constructs for understanding organizational change.

\section{Temporal Experience}

Although the importance of time in process research is widely accepted (Avital, 2000; Butler, 1995; Weick, 1995), scholars tend to exclude temporality as a meaningful construct in empirical work, thereby limiting the potential of process thinking to offer a genuine alternative for understanding practice and change. Much of the work to date has invoked a mechanical and rational view of time as an independent variable that can be captured in a series of snapshots. By contrast, understanding temporality as an embodied and lived experience admits the possibilities of emergence and continuity between past and future. This latter perspective holds the potential for multiple temporalities (Bluedorn \& Standifer, 2006), or what Nowotny called "pluritemporalism" (cited in Orlikowski \& Yates, 2002, p. 687), where different temporal rhythms exist simultaneously and may be experienced together. 
Our specific interest in this paper is to understand the lived experience of time as a flow that continuously connects past, present and future. Mead (1932) argued that this flow is experienced through events that cannot be properly understood in isolation from the process that generated them and into which they intercede (Bakken \& Hernes, 2006). For him, the present is a purely subjective, existential experience that draws resources from both remembered pasts and anticipated futures in order to perform meaningful action. This present should not be understood as an instant of clock time, but rather, as a movement that implies change. Meanings that arise through such a movement have performative implications in the present; it is the passage of many such presents that provides an ever-changing, emergent continuity of multiple pasts and futures.

\section{Agentic Action}

Emirbayer and Mische (1998) have combined Mead's ideas about temporality and the social nature of the self to develop a thoroughly processual theory of agency. They argued that to theorize the dynamics of agency, it is necessary to disaggregate this very broad construct into a set of constitutive, yet analytically significant dimensions. Specifically they suggested that action in the present is associated with practical-evaluative agency, which "entails the capacity of actors to make practical and normative judgments among alternative possible trajectories of action, in response to the emerging demands, dilemmas, and ambiguities of presently evolving situations" (Emirbayer \& Mische, 1998: 971). That is, practical-evaluative actions are directed towards enacting practical choices out of a repertoire of future possibilities, but within the constraints of past experience. When aspects of both the past and the future are brought together in present experience, there is a reflexive opportunity to mediate between them, choosing different, or modified actions. It is the actions arising from practical-evaluative agency that underpin change.

In the empirical study that now follows, we ask the question are there different temporalities engaged in the discursive construction of organizational change, and if so, how are these related to each other? We focus on the talk of a group of managers, identifying those present moment speech acts where the past and the future are immediately juxtaposed as practical-evaluative events. We then explore the patterns of action that are performed by their talk.

\section{DATA AND METHODS}

\section{Research Context}

This research was carried out in a small, arts sector company that was responsible for the management of three busy performance venues in a culturally vibrant city. The company interested us because of the complexity and ever-changing nature of its day-to-day business, as well as its reputation for innovative programming and events. We negotiated research access to observe and audio-record the regular weekly meetings of the senior management team over six months.

At the second meeting we attended, the Managing Director announced her wish to resolve a long-neglected structural issue concerning the function of duty managers in the company. A duty manager is the person on the spot who carries overall responsibility for any given event staged by the company. This role had always been undertaken by members of staff moonlighting over and above their daytime jobs in the company, and indeed most of the senior management team members had been duty managers at some stage in their careers. However, this arrangement was no longer adequate for the company's changing needs. Since any restructuring would impact existing 
staff, it was imperative that the relational aspects of change were managed with utmost sensitivity. Over the ensuing six months, the senior managers completely redesigned this role. It is this strategic restructuring that provides the empirical setting for this paper.

\section{Data Analysis}

The data that inform this study come from two distinct sources. Firstly, we used the verbatim transcripts of the senior managers' conversations in their meetings (more than 220,000 words of transcript). Secondly, we interviewed each member of the senior management team about one month after we had stopped attending their weekly meetings. These loosely structured interviews lasted for 60-90 minutes each, and produced a further 65,000 words of written transcript.

We began our data analysis by eliminating any topics in the meeting transcripts that concerned issues other than the duty management restructuring. This produced a reduced dataset of more than 45,000 words across 12 meetings. We then set about identifying instances of practicalevaluative agency within this dataset. Following Emirbayer and Mische (1998), we found 253 events where the remembered past and the anticipated future were immediately adjacent in the same speech act. These events were then coded according to the actions that they performed using the following taxonomy of performative actions: 'problematizing' recognises an unsatisfactory present situation, 'committing' concretises the present action required, 'justifying' normalises the present action as the right or best thing to do in the circumstances, 'imagining' considers the future potential and broader possibilities of the present situation, and 'recalling' draws on past patterns as a source of learning to inform present actions. We found that all 253 of the practical-evaluative events we had identified in the data could be categorized as one of these five actions so there was no need to formulate additional codes.

Next, we were interested in uncovering temporal patterns of intensification where specific types of practical-evaluative actions were sustained over a period of time. Many such patterns may be discerned in the data, but for the purposes of this paper, we have selected six extended sequences (S\#1-S\#6) that each uniquely illustrates a particular pattern of action. The events in these sequences emerge as amplifications of like-actions that create a certain performative momentum in the managers' talk.

The final stage of our analysis moved away from the real-time temporalities of fleeting events and sustained sequences, to examine the managers' retrospective reconstructions of the meanings that emerged from their meetings. We drew on interview data to identify enduring themes in the managers' perceptions of how the team had functioned during the duty management restructuring process. From this stage of the analysis we were able to discern three phases of interpretation (A, B and C), each of which is also associated with specific types and specific sustained patterns of practical-evaluative actions.

\section{FINDINGS}

\section{Phase A - Our Differences are our Strength}

This first phase was characterized by an extended and open brainstorming during which the managers probed each other's understandings of exactly what problems should be addressed by restructuring the duty management function. We identified a total of 101 practical-evaluative events during this phase, of which, 33 are coded as imagining, and 29 as problematizing. Of the 
remainder, 23 were coded as recalling, 11 as committing, and 5 as justifying. The dominance of imagining and problematizing is consistent with the general tone of problem elaboration and solution seeking that permeated the talk as each manager brought forward issues and ideas informed by her/his own experience and functional responsibilities. The free-flowing nature of the conversation allowed equal voice to every manager, providing ample opportunity for experiences to be shared, issues to be raised, and potential obstacles to be surfaced. There was a buoyant quality of openness to the talk that seemed to facilitate the abductive generation of new ideas and 'what if' scenarios.

As the talk in this phase proceeded, three sustained patterns of practical-evaluative action emerged. S\#1 comprised 27 practical-evaluative actions, as follows:

PPPPRPRCIPPPPIRCRIIPRPPRPIP

where $\mathrm{P}$ signifies problematizing, $\mathrm{C}$ committing, I imagining, and $\mathrm{R}$ recalling ( $\mathrm{J}$ justifying does not appear in this sequence). The dominance of problematizing actions (14 out of 27) suggests a pervasive tone of problematization, where the managers seem to reinforce each other's actions in a problematizing groove, while recalling and imagining actions offer resources to inform the collective problematizing. A few attempts at committing actions seem to be crowded out as too precipitate at this early stage in the restructuring process.

S\#2 comprised 10 practical-evaluative actions, of which, seven are imaginings:

IRIIIRIRII

Once again, we interpret this real-time, emergent pattern as evidence of reinforcing actions, whereby one manager's imagining invites other managers to pursue this same type of action in their talk. However, the pervasive tone of imagining actions in this sequence is quite different from the predominantly problematizing tone of S\#1.

Finally, S\#3 comprised 12 practical-evaluative events in an oscillating pattern of six problematizing and five imagining actions:

\section{PIPIPIPIIPRP}

This sequence demonstrates a quick fire pattern of articulating problems and solutions, which suggests abductive reasoning in action. Overall, the reinforcement of problematizing and imagining actions in these three sequences is consistent with the dominance of these two types of agentic action throughout Phase A.

The dynamics of problematizing and imagining in this phase were also reflected in the managers' retrospective sensemaking, which valued the heterogeneity of their knowledge and experience. This diversity amongst the senior managers was reflected in their talk, and underscored their willingness to engage with each other in sustained problematizing and imagining actions.

\section{Phase B - But our Differences have to be Managed}

This phase comprised 67 practical-evaluative actions: 28 committing, 14 imagining, 11 recalling, 7 problematizing, and 7 justifying. Although committing is the dominant form here, these actions were not all directed towards the same goal. Indeed, it was in this phase that personal agendas came to the fore, pointing to apparently irreconcilable differences between the senior managers. By comparison with Phase A, the talk here was much more guarded, and indeed, voices that had been very evident at the beginning of the process began to fade away. The dominance of committing is further reinforced in S\#4, which comprises 35 practical-evaluative actions, 19 of which are committing: 
Nowhere else in the entire dataset is there such a concentration of this committing type of action. Although all the other action types (P, J, I and R) do occur in this sequence, none of them achieves the same degree of intensification. Throughout $\mathrm{S} \# 4$, actions shifted from a variety of different commitments intended to move the process forward, to a more specific commitment to an agreed path forwards. Whereas Phase A seems to be characterized by divergent, abductive, 'what if' reasoning, Phase B is better understood in terms of the convergent, inductive process of moving from a range of potential options to a single plan for strategic action.

The managers' retrospective reconstructions of this phase focused on the exclusion of individuals from decisions, and the need to constrain diversity in order to achieve the desired outcomes. In the post-process interviews, managers reflected on this phase in terms of an erosion of trust amongst the team members. Evidently the restructuring process became politically charged during Phase B as different positions became more hardened and immutable. This political process is reflected in the intensity of committing actions, which served to demarcate the lines of debate.

\section{Phase C - We Speak with one Voice}

With an apparent consensus accomplished, the managers now turned their attention to deductively refining the details of implementation. Phase $\mathrm{C}$ comprised 85 practical-evaluative actions, of which 27 were justifying, 29 recalling, 16 committing, 7 problematizing, and 6 imagining. The dominance of justifying and recalling is the defining character of this phase, distinguishing it from the committing of Phase B, and the combination of problematizing and imagining in Phase A. The talk here was focussed on naturalizing the intended course of action within the context of past practices. These trends are reinforced by two sequences of concentrated activity. S\#5 comprised 14 practical-evaluative actions, 11 of which are recalling:

\section{RRRJRRRPRRRRIR}

while S\#6 comprised 20 practical-evaluative actions, 12 of which are justifying:

\section{JCJJRCJRJJJJRJJPCJPJ}

Retrospective reflections on Phase $\mathrm{C}$ focused on the practice of uniting in support of the decision taken, and acting in the best interests of the company. Ultimately then, it seems that the managers came to a shared view that although the restructuring was a difficult and unpleasant process, it was nevertheless necessary for the future of the company. The justifying and recalling actions that dominated Phase $\mathrm{C}$ were critical in arriving at this shared strategic position.

Taken together, there are several interesting patterns of agentic action that characterise this entire restructuring process. Firstly, the problematizing and imagining actions that dominated Phase A declined in intensity though Phases B and C. Conversely, the justifying actions that are dominant in Phase $\mathrm{C}$ built up progressively through Phases $\mathrm{A}$ and $\mathrm{B}$, while committing actions reached their peak intensity in Phase $\mathrm{B}$, falling off in frequency in the adjacent phases. In contrast to these rising and falling patterns of activity, the intensity of recalling actions remained fairly steady throughout the process, providing the ground upon which this strategic process unfolds.

\section{DISCUSSION}

We see the whole restructuring process unfolding as a continuous flow through three phases of reasoning, each of which is characterized by particular types of action. The trend from abductive idea generation, through the inductive process of forming a working proposition, and on to the deductive testing of this proposition is consistent with the dialogical process of inquiry that was 
originally articulated by John Dewey (see Lorino, Tricard, \& Clot, 2011). However, Dewey did not address the temporal experience of change. Our findings demonstrate three different temporalities: fleeting practical-evaluative actions, sustained sequences of actions, and enduring reconstructions of meaning. The first of these is associated with the momentary experience when remembered pasts and anticipated futures are juxtaposed in the same speech act. It is here that the performativity of talk is revealed, showing how different types of action arise from different types of talk. Although this experience is ephemeral, Emirbayer and Mische (1998) argued it is fundamental to a properly temporal understanding of agency. Next, we have shown that, far from being randomly distributed across a change process, different types of practical-evaluative actions may be concentrated together as sustained sequences that imbue certain pervasive movements to different phases of the process. The patterning of these sequences is an emergent, self-organizing property of the managers' talk rather than anything that is intentionally constructed. As temporal concentrations of practical-evaluative actions, they bring together successions of remembered pasts and anticipated futures, thus providing a sense of continuity. Finally, in addition to the real-time dynamics of practical-evaluative actions and their sequences, we have also identified a third temporality that is concerned with the retrospective reconstruction of meanings from remembered pasts. Here, actors make sense of what has happened to them by reconstructing the narrative of their past experience. This reconstructive temporality is inherently recursive, producing a continuity of meaning-making amongst the members of a group. It is in the interplay between these three temporalities that we see the creative emergence (and submergence) of new ideas and directions that, in turn, become embedded in strategic practice as reconstructed meanings.

Each of the three temporalities is immanent within, and dependent upon the others. Practical-evaluative actions are not necessarily always gathered together in sustained sequences of action, but when they are, they acquire a performative force that is capable of transforming the situation. Thus we see sustained sequences as temporal mediators of the more enduring reconstructions of meaning that are being continuously renegotiated in an open-ended and emergent narrative. In the empirical case we have presented here, the transformative function of sustained sequences is demonstrated by changing problem into solution, trust into distrust, general into particular, dissensual into consensual, and specific into broad implications. Ultimately it is in the conflux of these three temporalities that we understand strategic practice in all its dynamic complexity (Hendry, 2000; Mintzberg \& Waters, 1985). It is not simply a decision taken at a moment in time, and neither is it just the reproduction of past practices. Rather, we understand organizational practice as a swirling process that continuously reconstructs meanings by bringing remembered pasts and anticipated futures to bear on the unfolding meanings of present actions.

The argument that we have presented here is directed at one of the most perennial problems faced by managers, namely how to understand and better manage the complexities of strategic organizational change. By weaving together talk, temporality and agency, we have offered theoretical, empirical and practical insights that we suggest go some way towards opening up the black box of managerial practice in the context of change. Our analysis has a distinctively processual focus on the flux and flow of changeful organizational practice, and it is this commitment to process that differentiates our work, both theoretically and empirically, from more conventional studies that seek stability rather than emergence in organizational change.

\section{REFERENCES AVAILABLE FROM THE AUTHORS}

